BMJ Paediatrics Open

\title{
Literature review of medication administration problems in paediatrics by parent/caregiver and the role of health literacy
}

Dania Talaat Dahmash (D) , Zakia B Shariff, Daniel J Kirby, David Terry, Chi Huynh

To cite: Dahmash DT, Shariff ZB, Kirby DJ, et al. Literature review of medication administration problems in paediatrics by parent/ caregiver and the role of health literacy. BMJ Paediatrics Open 2020;4:e000841. doi:10.1136/ bmjpo-2020-000841

- Additional material is published online only. To view, please visit the journal online (http://dx.doi.org/10.1136/ bmjpo-2020-000841).

The review preliminary results was published on the BMJ (Archives of Disease in childhood) after an abstract was submitted for the NPPG 2018 conference for the purpose of poster presentation.

Received 17 August 2020 Revised 9 November 2020 Accepted 9 November 2020

Check for updates

(C) Author(s) (or their employer(s)) 2020. Re-use permitted under CC BY-NC. No commercial re-use. See rights and permissions. Published by BMJ.

Aston Pharmacy School, College of Health and Life Sciences, Aston University, Birmingham, United Kingdom

Correspondence to Dr Chi Huynh; c.huynh3@aston. ac.uk

\section{ABSTRACT}

Objective To identify studies that highlighted medication administration problems experienced by parents and children, which also looked at health literacy aspect using a validated tool to assess for literacy.

Study design Ten electronic databases were systematically searched and supplemented by hand searching through reference lists using the following search terms: (1) paediatric, (2) medication error including dosing error, medication administration error, medication safety and medication optimisation and (3) health literacy. Results Of the (1230) records screened, 14 studies were eligible for inclusion. Three analytical themes emerged from the synthesis. The review highlighted that frequencies and magnitudes of dosing errors vary by the measurement tools used, the dose prescribed and by the administration instruction provided. Parent's sociodemographic, such as health literacy and language, is a key factor to be considered when designing an intervention aimed at averting medication administration errors at home. The review summarised some potential strategies that could help in reducing medication administration errors among children at home. Among these recommendations is to show the prescribed dose to the parents or young people along with the verbal instructions, as well as to match the prescribed dose with the measuring tool dispensed, to provide an explicit dose intervals and pictographic dosing instructions.

Conclusion The findings suggest that in order to optimise medication use by parents, further work is needed to address the nature of these issues at home. Counselling, medication administration instructions and measurement tools are some of the areas in addition to the sociodemographic characteristics of parents and young people that need to be considered when designing any future potential intervention aimed at reducing medication errors among children and young people at home.

\section{INTRODUCTION}

When it comes to medication administration for children at home, a significant burden of responsibility relies on the parents or on the patients themselves. ${ }^{1}$ It has been documented that medication administration errors among children is well known to occur. ${ }^{2}$ Previous studies recognised that more than $40 \%$ of

\section{What is known about the subject?}

Medication administration errors occur frequently among children.

- Parent's health literacy could be associated with medication administration problems in children.

- Studies examining parent administrator paediatric medicine accuracy were mainly from one particular research group in the USA with participant parents using non-standardised measuring tools.

\section{What this study adds?}

The nature of medication administration error's happening at home are not well documented across each age group.

The need to explore parents and patients perspective in regards to medication administration challenges happening at home.

parents and caregivers make dosing errors in an outpatient setting. ${ }^{34}$ The inability to administer medication correctly may result in adverse drug events and poor patient clinical outcomes. ${ }^{5}$ Causes of medication administration problems at home are multifactorial and potentially depend on various factors. ${ }^{2}$ So, in order to improve medication administration by parents and patients, an initial assessment of the current problems and factors that may contribute to this issue must be identified first.

Previous studies have recognised potential factors that can contribute to clinician-led medication administration errors in children, but there have been no studies recording both the types and risk factors that can contribute towards caregiver's medication administration problems as well as young people. ${ }^{67}$ According to the European Health Literacy Survey, conducted across eight different countries, the prevalence of low health literacy levels varies from $29 \%$ to $62 \% .^{89}$ 
Owing to this, high prevalence of low health literacy levels and its potential association with medication administration issues among children. This review aimed at identifying studies that highlighted medication administration problems experienced by parents and children, which also looked at health literacy aspect using a validated tool to assess for literacy. In this systematic review, the common medication administration problems occurring at home as well as the potential causalities and risk factors other than health literacy that further could contribute to medication administration errors have been highlighted.

\section{Methods}

This review was conducted in accordance with the Cochrane Handbook for Systematic Reviews, and followed Preferred Reporting Items for Systematic Reviews andMeta-Analyses (PRISMA) reporting guidelines. ${ }^{11}$ The review protocol is registered on PROSPERO (ID: CRD42018091590).

\section{Patient and public involvement}

There was no patient and public involved in the design, or conduct, or reporting, or dissemination of this review.

\section{Eligibility criteria}

Studies were eligible for inclusion if they were related to medication administration errors among children and adolescent between the ages of $0-18$ years old as per the WHO definition of population age group. This includes studies reporting medication-related problems outside the clinical setting; where the parent or the child is responsible for administering or taking the medication. Studies must have assessed the health literacy levels of the participants using a validated health literacy assessment tool. Any study that looked only at education levels of the participants without assessing the literacy levels was excluded. There were no restrictions on the date of publication, only English language articles studies where included.

\section{Search strategy}

The search strategy was designed initially by the research team and verified by an information specialist using the Population, Intervention, Comparison and Outcomes model. The reviewer (DTD) systematically searched PubMed, Scopus, Web of Science, Cochrane Library, OpenGrey, NHS Digital Department of Health Office for National Statistics, BBC News, Bielefeld Academic Search Engine, E-thesis Online Service and Conference proceedings through Web of Science for studies from database inception to September 2020.

Search terms summarised in online supplemental material, table S1 included a comprehensive list of synonyms and multiple Boolean operators relating to: (1) paediatric (2) medication error including dosing error, medication administration error, medication safety and medication optimisation and (3) health literacy. DTD further performed reference tracking of all included studies to identify any potential studies to be included in the review.

\section{Study selection}

Two reviewers (DTD, ZBS) independently evaluated each study for eligibility to reduce bias using the inclusion criteria above. The titles and/or abstracts of all identified studies were reviewed independently, and full manuscripts that appeared to potentially relevant.

\section{Data extraction process and synthesis}

Two reviewers (DTD and ZBS) independently extracted data using a standardised predefined spreadsheet. Inconsistencies in extracted data were resolved through consensus discussion by a third reviewer $(\mathrm{CH})$, if necessary. Results were synthesised and summarised according to analytical themes. Thematic analysis was opted by the research team as it is known for its flexibility and ability of identifying patterns of meaningful information within the data. ${ }^{12}$

\section{Quality appraisal}

The quality of the included papers was independently assessed by two reviewers (DTD, ZBS) using Critical Appraisal Skills Programme checklists. ${ }^{13} 14$ Discrepancies were resolved through discussion and consensus.

\section{RESULTS}

A total of 672 citations were retrieved from the database and other searches. After screening titles and abstracts, 38 publications were obtained in full text and assessed for suitability. Of which, 14 met the inclusion criteria and were included in the analysis (see figure 1 for PRISMA flow chart) ${ }^{15-28}$ See online supplemental material, table S2 for reasons of exclusion.

The details of the 14 studies are presented in (tables 1 and 2) ${ }^{15-28}$ The majority of the included studies were published in the last 12 years. All of the studies $(n=14)$ took place in the USA.

Overall, 11 studies recruited parents or caregivers of children aged between 30 days to less than 9 years old, 2 studies had recruited parents with no age limitations of the child and 1 study recruited only women of childbearing age. The majority of the studies $(n=13)$ did report the ethnic composition of their recruited sample and they were vastly Hispanic or black African American parents or caregivers. One study had only exclusively recruited women from a white ethnic background. ${ }^{22}$

\section{Quality appraisal}

The results from the quality appraisal are shown in online supplemental material, tables S3 and S4. All identified studies were included in the final synthesis with a greater emphasis on the higher quality studies.

\section{Synthesis of results}

The data from the 14 studies were analysed and three analytical themes emerged from the analysis and a 


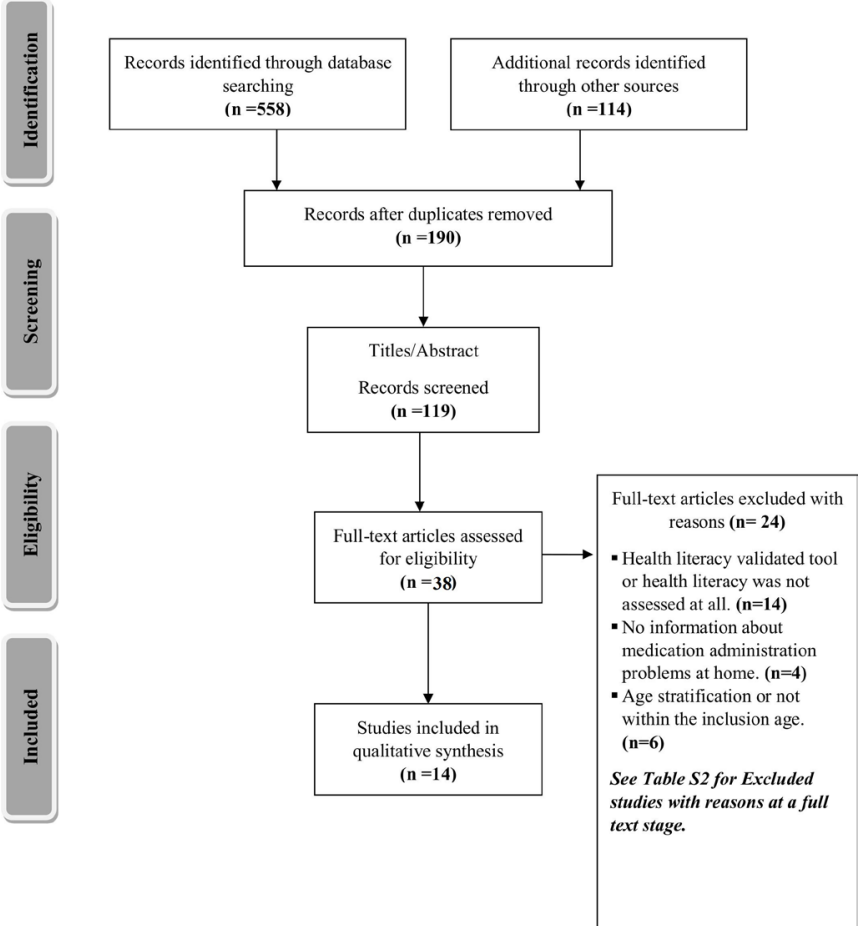

Figure 1 Flow diagram for the study selection based on Preferred Reporting Items for Systematic Reviews andMetaAnalyses flow diagram.

summary of the review results are demonstrated in figure 2.

\section{Types and causes of medication administration errors among} children led by parents or child outside a clinical setting

Eight of the included studies indicated that paediatric dosing errors are among the most common medication errors made by parents. ${ }^{1518-21232426}$ Among these studies, two randomised trials identified that overdosing errors are more common among parents. ${ }^{23}{ }^{24}$ While another cross-sectional study looking at parents with child on a short course prescribed medication reported that the majority of the parents measured below the prescribed dose. ${ }^{15} \mathrm{~A}$ study by Morrison $e t a l^{20}$ reported that parents who made underdosing errors made more dosage errors and frequency errors compared with those who made an overdosing error.

From the included studies, it was noticed that the magnitude and frequency of dosing errors by parents were influenced by two factors: measurement tool used by parents and the dose volume (amount) . In one study, parents stated that non-standardised kitchen spoon was their primary dosing tool. ${ }^{17}$ Two studies reported that errors were more common with measuring cups than with syringes, in particularly with small dose volumes (amounts). ${ }^{2124}$ In a cross-sectional study conducted in the USA, the majority $66 \%$ of the parents considered oral syringes are the best tool for dosing accuracy, while $23.5 \%$ believed that cups were the best; however, few $10.1 \%$ believed that dosing spoon, measuring spoon, kitchen teaspoon and droppers were the best. ${ }^{27}$ Another study reported that larger dosing errors $(>40 \%$ deviation of the recommended dose) were made by parents using cups with printed marking and etched markings; this was thought to be due to confusion about teaspoon versus tablespoon instructions, assumptions that the cup is the unit of measure and the full cup is the dose. ${ }^{16}$ Labels and units of the prescribed medication were contributing factors to dosing errors. ${ }^{24}$ Parents made significant dosing errors when the units found on the medication bottle label were not similar to the units used on the dosing tool. ${ }^{24}$ Parents who used teaspoon/tablespoon units were likely to use a non-standardised dosing instrument and make errors in measuring the prescribed and intended dose. ${ }^{19}$ The final potential factor was the type of instructions provided. For liquid medication, less errors were seen among parents who were provided with text-pluspictogram instructions $43.9 \%$ compared with text-only instructions $59.0 \%$ and this group were also less likely to make overdosing errors. ${ }^{26}$ Parents who received standard medication counselling were $47.8 \%$ more likely to make dosing errors when compared with parents who received pictogram instruction $(5.4 \%){ }^{25}$

\section{Factors related to patients or caregivers and medication errors Health literacy}

Health literacy of caregivers in the studies were assessed; six conducted further analyses of its influence on dose accuracy and other cofactors related to medication errors. Yin et $a l^{17}$ reported that caregivers with inadequate or marginal health literacy were more likely to use a non-standardised dosing instrument and further lacked knowledge on weight-based dosing for over the countermedication when compared with caregivers with adequate health literacy. Another study by Yin et $a l^{16}$ found a significant association between health literacy and dosing errors using cups and dosing spoons. In adjusted analysis conducted by Williams et $a l,{ }^{27}$ they found that there was a strong association between health literacy levels and measurement tool preference in particular cups, parents with limited literacy reported that dosing cups were the tool of choice most of the time $(\mathrm{aOR}=2.4)$. The use of a teaspoon/tablespoon was associated with errors in the intended dose for those with low health literacy but not for those with adequate health literacy. ${ }^{19}$ Harris $e t a l^{21}$ identified that parents with limited health literacy and limited English proficiency (LEP) made the most dosing errors. Similarly, Samuels-Kalow et $a l^{18}$ revealed that parents with inadequate and marginal health literacy committed dosing errors, but the sample size of this group was small compared with the adequate health literacy group.

\section{Language}

Association between health literacy and lack of knowledge of weight-based dosing varied by English speaking caregiver's. For English speaking caregivers, $88.6 \%$ of inadequate or marginal health literacy caregivers were unaware of weight-based dosing in comparison to $54.1 \%$ 


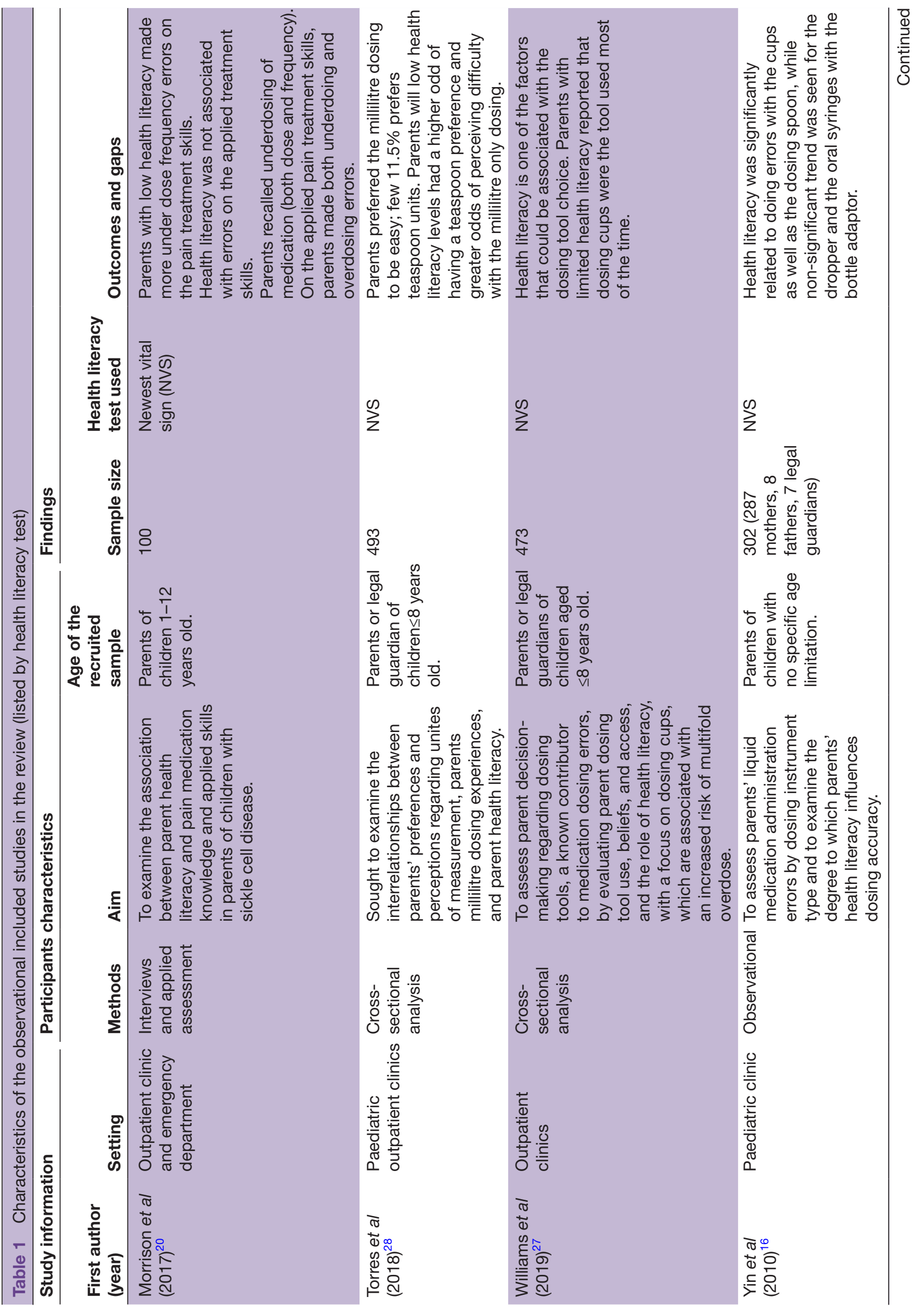




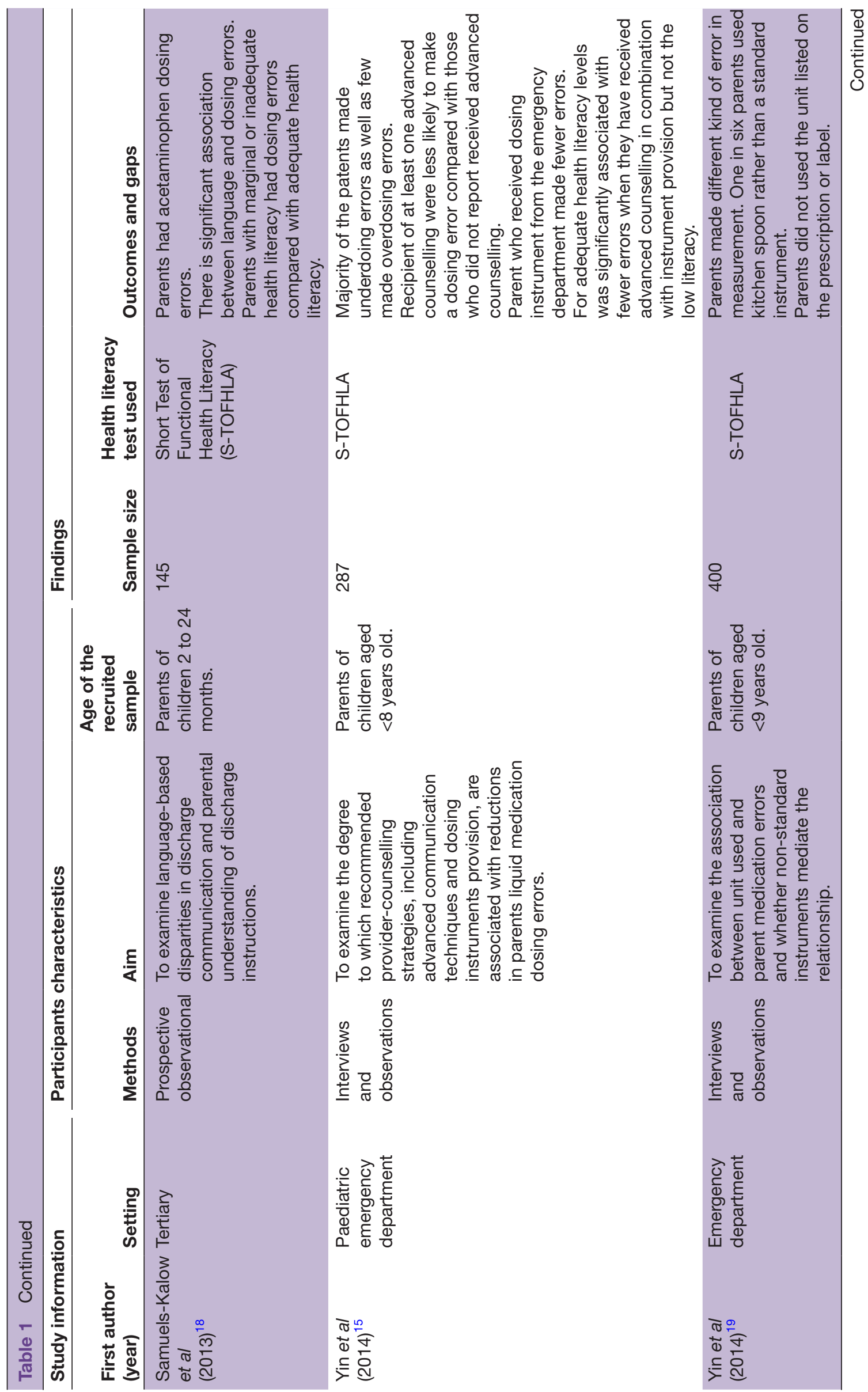




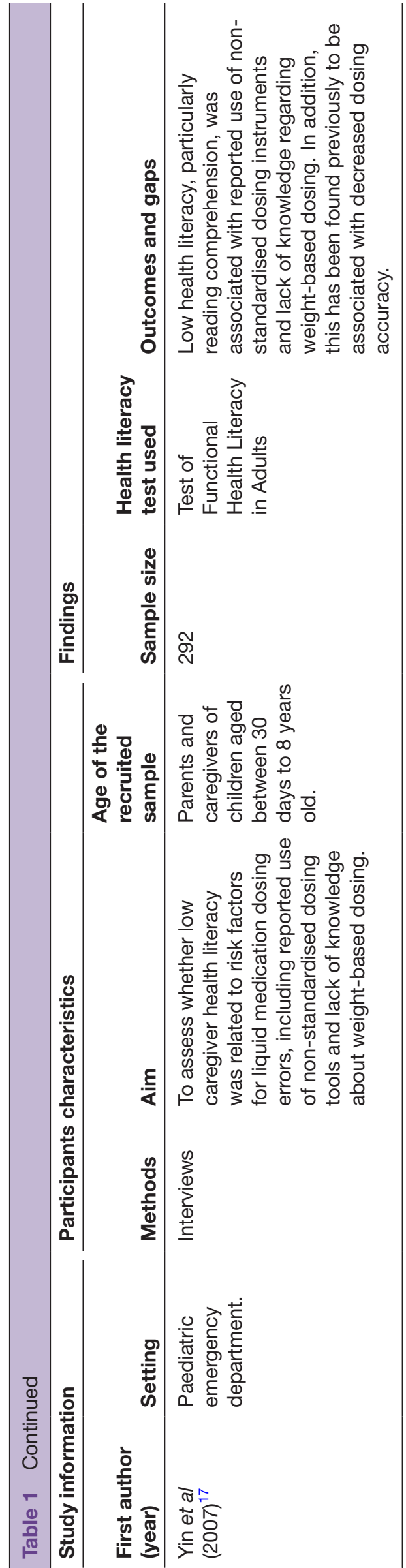

of caregivers with adequate health literacy. ${ }^{17}$ In contrast, Yin $e t a l^{26}$ found that there was no significant relation between dosing error and LEP. However, there were some differences in teaspoon-associated errors in measurement by language. ${ }^{19}$

\section{Comprehension and recall of instructions in relation to parent sociodemographic status}

Yin $e t a l^{25}$ reported that parents from a low sociodemographic status who were prescribed a daily dose and who received a simple language, pictogram instructions sheets, were less likely to make errors in knowledge of dose frequency and dose accuracy compared with the control group who received standard medication counselling $(0 \%$ vs $15.1 \%)$. Participants among the interventional group were less likely to report incorrect medication preparation related to shaking the medication before administration for both daily doses $(10.9 \%$ vs $28.3 \%, \mathrm{p}=0.04)$ and as needed medication $(21.5 \%$ vs $43.0 \%) .{ }^{25}$ Participants in the interventional group were less likely to use a non-standardised measurement tool compared with the parents in the standard group (daily dose: $93.5 \%$ vs $71.7 \%$; as needed: $93.7 \%$ vs $74.7 \%) .{ }^{25}$ Torres $e t a l,{ }^{28}$ a cross-sectional study that analysed data from a randomised control study, looked at parents preference and perceptions in regards to units of measurements. It was found that over $80 \%$ of the parents perceived a change to millilitre only instructions would be easy in comparison to $14 \%$ found it some how hard and $4.1 \%$ very hard.

Interventions aimed at reducing medication administration errors occurring among children outside a clinical setting Parent's sociodemographic factors

Four studies suggested that parental sociodemographic risk factors should be considered when designing an intervention aimed at averting medication administration errors. ${ }^{16} 172126$ Among these factors were parents' health literacy as well as language. Kalow et al suggested that efforts to streamline interpreter services must be continued as well, to having a more formalised approach in place to elucidate the patient's preferred language for communication. $^{18}$

\section{Counselling and training}

Three studies suggested that provisional dose counselling (showing the patient how to prepare the dose) in combination with verbal counselling could be associated with less dosing errors. ${ }^{15} 1723$ A study by Yin et $a l^{15}$ indicated that errors occur across different counselling approaches, and they have recommended developing new strategies to ensure that parents understand medication instructions as well as the need for further research to identify the best counselling strategies and how to incorporate these within clinical practice. Yin $e t$ $a l^{24}$ suggested the need for intensive teaching, training and coaching programmes that can accommodate for different parental health literacy levels. 


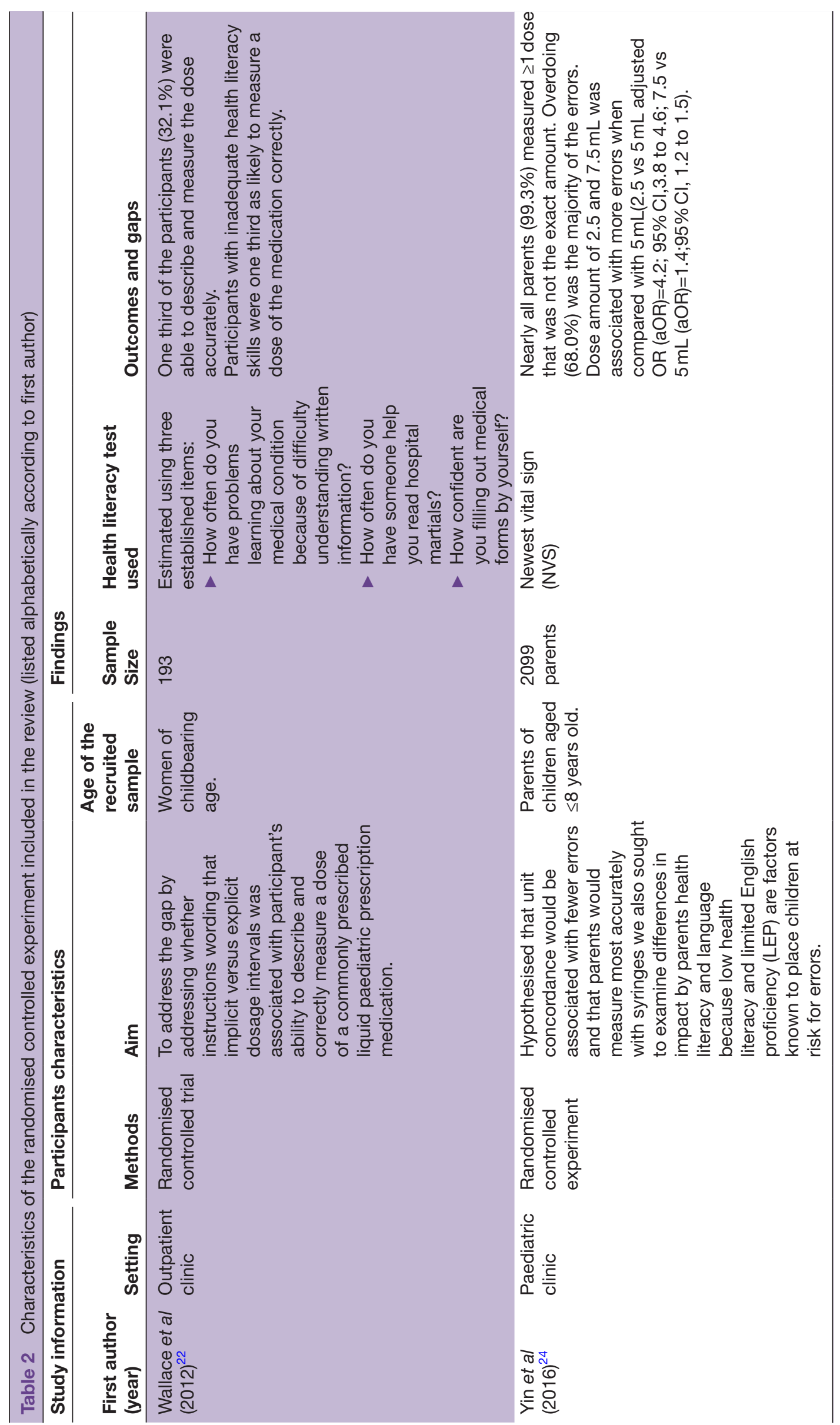

홍 


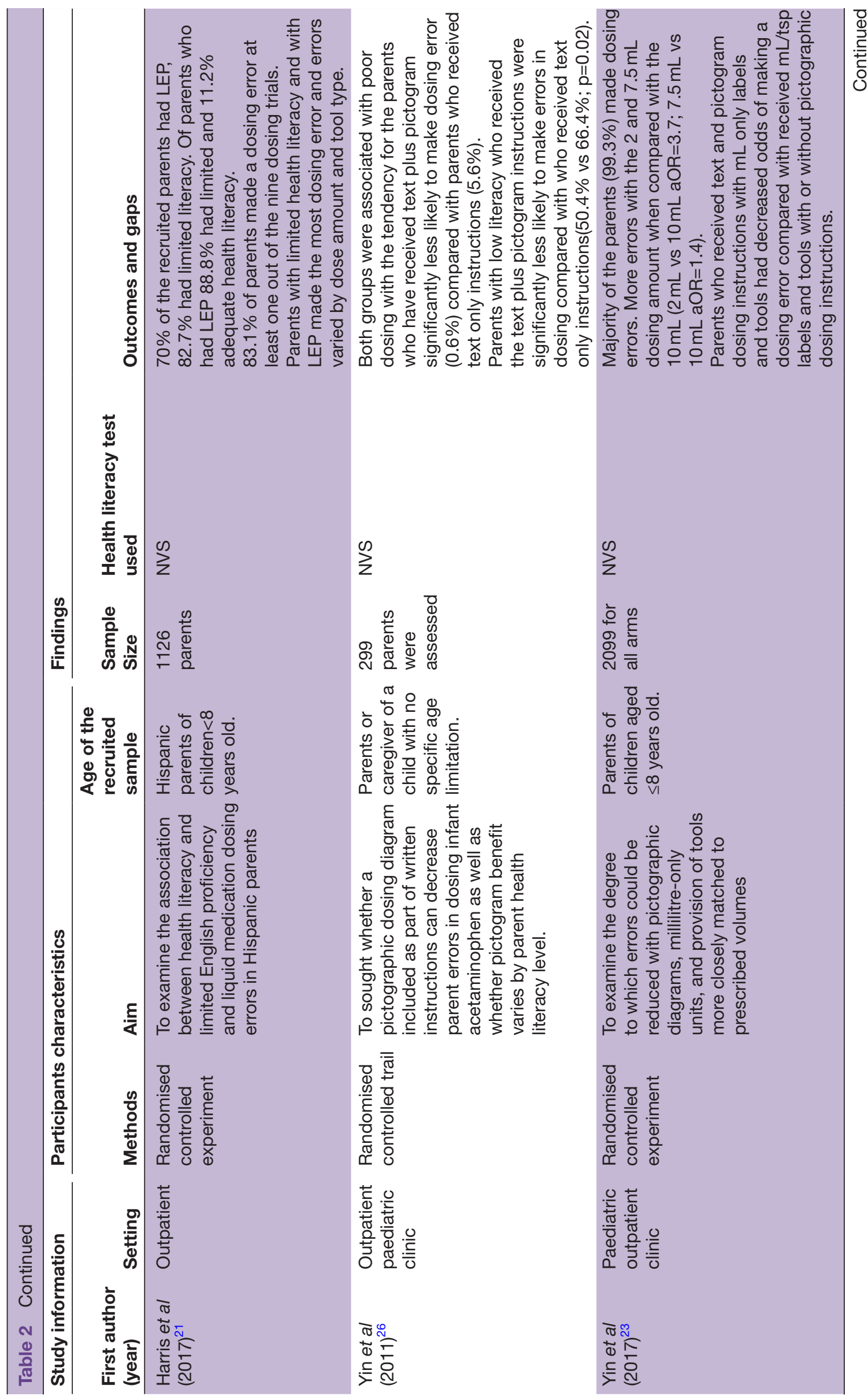




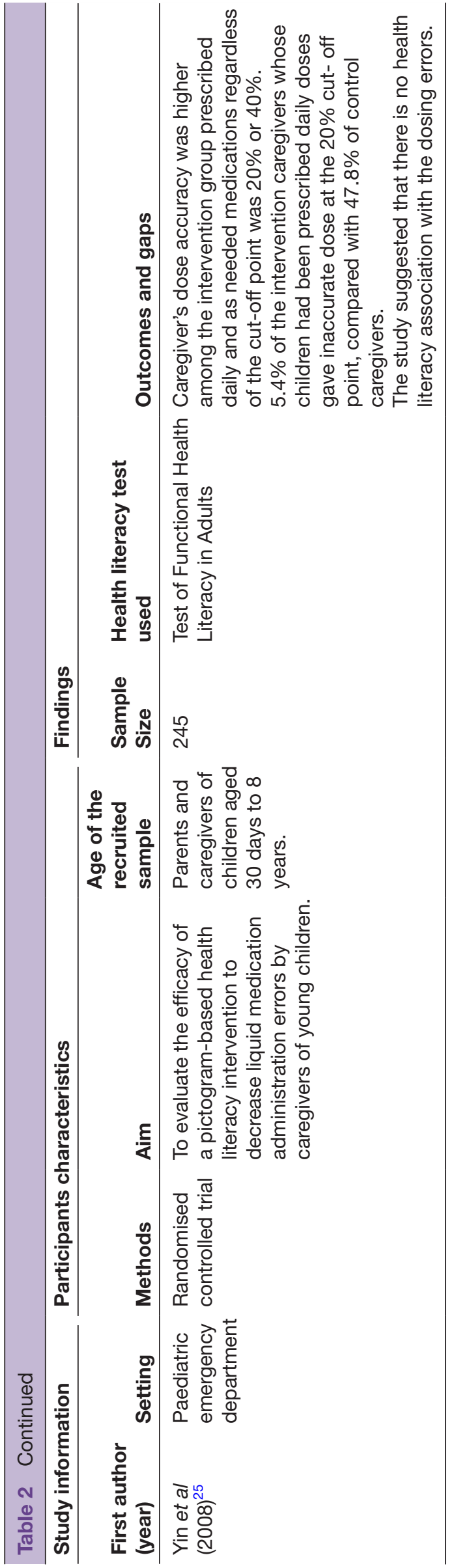

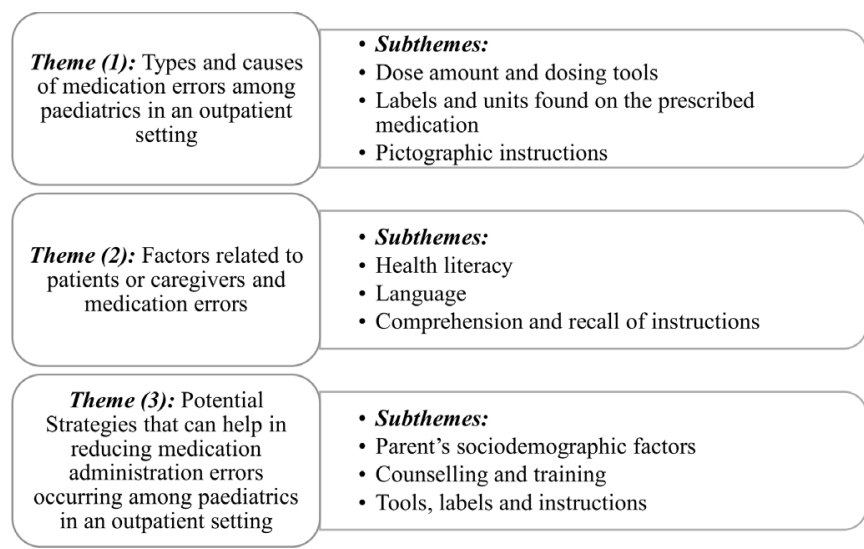

Figure 2 List of the review results.

\section{Tools, labels and instructions}

Yin et al suggested a promising strategy that could potentially help to reduce paediatric-dosing errors, which was to match the dosing tool with the prescribed dose volume and move towards more simplified numerical markings on the measurement tools as well as to move to millilitreonly units. ${ }^{24} 26{ }^{28}$ Wallace $e t a l^{22}$ indicated in his study that some parents would prefer instructions with explicit dosage intervals with the exact time and dose to be specified on the label. Harris $e t a l^{21}$ suggested improving the availability of language concordant labels that could accommodate for different health literacy levels. Three studies from this review strongly suggested the importance of using pictographic dosing instructions and how it could be a positive aid in reducing paediatric dosing errors. ${ }^{23} 2526$ Majority of parents would be comfortable with millilitre dosing instructions only.

\section{DISCUSSION}

The results of this study suggest that parents appear to make a range of medication errors, particularly with liquid medications as documented by prior studies that were conducted also in the USA as well as studies from this review. ${ }^{2} 42325$ The majority of the included studies indicated that dosing errors were among the most common medication errors made by parents, which is consistent with another study, which was conducted on Spanish-speaking Latino parents. ${ }^{15} 19212529$ This review identified possible causality behind parents dosing errors other than just the effect of health literacy; these errors could be linked to the: dose volume prescribed, measurement tools used, units used on the labels and the instructions provided.

Although standardised measurement tools are usually dispensed with the prescribed liquid medications in the UK, this review identified that the studies published in the USA indicated that parents still use non-standardised liquid dosing tools as their primary measuring tool; this has been previously linked with medication administration errors by both Yaffe et al and McMahon $e$ a $a .^{3031}$ The review found that pairing the medication labels to the 
closest measurement tool size, particularly for millilitreonly labels and tools, could be associated with a reduction in parent dosing and administrating error rates, as well as a decrease in the likelihood of parents using nonstandardised measurement tools as suggested by another research. ${ }^{1932}$

The review showed that the use of simple pictographicbased medication instructions with explicit dosage intervals could reduce dosing errors by parents. This finding was consistent with previous existing data from both South and West Africa as well as the USA regarding the use of pictographic illustrations as a supportive tool to aid parents in administering medication to their children correctly. ${ }^{33-41}$ Potentially, this could benefit both parents and caregivers with limited or low health literacy levels.

Our findings are consistent with prior USA studies investigating the link between adult's sociodemographic factors, particularly health literacy, and medication administration problems. ${ }^{42-45}$ Four studies explicitly highlighted that sociodemographic factors, such as health literacy and language, must be incorporated into any future intervention that aims to reduce parental dosing and administration errors.

The results of the review highlighted several interventions to aid parents and patients to potentially reduce medication administration errors at home. This include the use of plain language combined with provision of using the dosing tool provided as well as incorporating pictographic instructions which were consistent in four of the included studies. ${ }^{15232526}$ Pictographic-plain instructions significantly improve the accuracy of dosing and administering medication to children especially for those parents with insufficient health literacy. ${ }^{25} 26$

This study emphasised potential areas that could be incorporated into real practice that could help with reducing medication administration errors done by parents/caregivers and patients. Potential strategies include personalised training and coaching that accommodate different health literacy levels and languages as well as the possibility to match the dosing tool with the prescribed volume alongside the use of millilitre units.

Our review is subject to several limitations. There were two major limitations to our study. First, we only included studies in English, so publication bias may exist and non-English studies that are related to this topic might have been missed. Second, we only included studies that evaluated literacy using a validated tool. This resulted in only studies from the USA being included. The excluded studies that are of relevance to the topic, but outside the scope of this review are listed in (online supplemental table S2). Literacy is a problem worldwide, but of greater importance in low-income and middle-income countries. Future reviews should include these studies by broadening the search strategy.

Furthermore, although the study aimed at including medication administration challenges for younger people aged between 16 and 18 years old, however, none was included, as they did not pass the eligibility criteria for this review. Future research are needed where younger people aged 16-18 years old are included as participants. In addition, the generalisability of the study results maybe low; this is because the majority of the studies were conducted in the USA and emerged from the same research group Yin et al. This research group has highlighted several limitations in their studies, such as the use of hypothetical scenarios that might not be a true reflection on how parents measure the dose at home. ${ }^{16} 232426$ For some randomised trial studies in this review, it was difficult for the research team to maintain blindness as some of the participants revealed their allocated group, while for the cross-sectional studies, no conclusion of the causes could be drawn. ${ }^{1719}{ }^{25}$ Finally, the date of publication for one of the studies was 13 years old, ${ }^{17}$ which would not take into account the changes that have occurred in terms of interventions that would vary locally, nationally and internationally. However, this review highlights that non-standard dosing still occurs to date due to parent preference based on recent evidence in 2018. ${ }^{28}$

\section{CONCLUSIONS}

The findings suggest that in order to optimise medication use by parents, further work is needed to address the nature of these issues at home. Counselling, medication administration instructions and measurement tools are some of the areas in addition to the sociodemographic characteristics of parents and young people are among the factors to be considered when designing any future potential intervention aimed at reducing medication errors among children and young people at home.

Twitter Dania Talaat Dahmash @DaniaDahmash

Contributors All authors have contributed in this manuscript.

Funding Aston University, Birmingham, UK, is funding Dania Dahmash PhD project, which as part of her project this review was conducted.

Competing interests None declared.

Patient consent for publication Not required.

Provenance and peer review Not commissioned; externally peer reviewed.

Data availability statement No data are available. All data relevant to the study are included in the article or uploaded as supplementary information. All data relevant to this study is included within the manuscript.

Supplemental material This content has been supplied by the author(s). It has not been vetted by BMJ Publishing Group Limited (BMJ) and may not have been peer-reviewed. Any opinions or recommendations discussed are solely those of the author(s) and are not endorsed by BMJ. BMJ disclaims all liability and responsibility arising from any reliance placed on the content. Where the content includes any translated material, BMJ does not warrant the accuracy and reliability of the translations (including but not limited to local regulations, clinical guidelines, terminology, drug names and drug dosages), and is not responsible for any error and/or omissions arising from translation and adaptation or otherwise.

Open access This is an open access article distributed in accordance with the Creative Commons Attribution Non Commercial (CC BY-NC 4.0) license, which permits others to distribute, remix, adapt, build upon this work non-commercially, and license their derivative works on different terms, provided the original work is properly cited, appropriate credit is given, any changes made indicated, and the use is non-commercial. See: http://creativecommons.org/licenses/by-nc/4.0/.

ORCID iD

Dania Talaat Dahmash http://orcid.org/0000-0001-6508-0994 


\section{REFERENCES}

1 Walsh K, Ryan J, Daraiseh N, et al. Errors and nonadherence in pediatric oral chemotherapy use. Oncology 2016;91:231-6.

2 Frush KS, Luo X, Hutchinson P, et al. Evaluation of a method to reduce over-the-counter medication dosing error. Arch Pediatr Adolesc Med 2004;158:620-4.

3 Li SF, Lacher B, Crain EF. Acetaminophen and ibuprofen dosing by parents. Pediatr Emerg Care 2000;16:394-7.

4 Simon HK, Weinkle DA. Over-The-Counter medications. do parents give what they intend to give? Arch Pediatr Adolesc Med 1997;151:654-6.

5 Sil A, Sengupta C, Das AK, et al. A study of knowledge, attitude and practice regarding administration of pediatric dosage forms and allied health literacy of caregivers for children. J Family Med Prim Care 2017;6:636-42.

6 Walsh KE, Kaushal R, Chessare JB. How to avoid paediatric medication errors: a user's guide to the literature. Arch Dis Child 2005;90:698-702.

7 McPhillips HA, Stille CJ, Smith D, et al. Potential medication dosing errors in outpatient pediatrics. J Pediatr 2005;147:761-7.

8 Rudd RE. Health literacy skills of U.S. adults. Am J Health Behav 2007;31(Suppl 1):8-18.

9 Sørensen K, Pelikan JM, Röthlin F, et al. Health literacy in Europe: comparative results of the European health literacy survey (HLS-EU). Eur J Public Health 2015;25:1053-8.

10 Moher D, Liberati A, Tetzlaff J, et al. Preferred reporting items for systematic reviews and meta-analyses: the PRISMA statement. Int $J$ Surg 2010;8:336-41.

11 Higgins J, Green S. Cochrane Handbook for systematic reviews of interventions, 2011.

12 Clarke V, Braun V, Hayfield N. Thematic analysis. qualitative psychology: a practical guide to research methods, 2015: 222-48.

13 Critical Appraisal Skills Programme. CASP (randomised controlled trial) checklist, 2018. Available: https://casp-uk.net/wp-content/ uploads/2018/03/CASP-Randomised-Controlled-Trial-Checklist2018 fillable form.pdf

14 Critical Appraisal Skills Programme. CASP (qualitative) checklist, 2018. Available: https://casp-uk.net/wp-content/uploads/2018/03/ CASP-Qualitative-Checklist-2018 fillable form.pdf

15 Yin HS, Dreyer BP, Moreira HA, et al. Liquid medication dosing errors in children: role of provider counseling strategies. Acad Pediatr 2014;14:262-70.

16 Yin HS, Mendelsohn AL, Wolf MS, et al. Parents' medication administration errors: role of dosing instruments and health literacy. Arch Pediatr Adolesc Med 2010;164:181-6.

17 Yin HS, Dreyer BP, Foltin G, et al. Association of low caregiver health literacy with reported use of nonstandardized dosing instruments and lack of knowledge of weight-based dosing. Ambul Pediatr 2007;7:292-8.

18 Samuels-Kalow ME, Stack AM, Porter SC. Parental language and dosing errors after discharge from the pediatric emergency department. Pediatr Emerg Care 2013;29:982-7.

19 Yin HS, Dreyer BP, Ugboaja DC, et al. Unit of measurement used and parent medication dosing errors. Pediatrics 2014;134:e354-61.

20 Morrison AK, Myrvik MP, Brousseau DC, et al. Parents' pain medication underdosing is associated with more emergency department visits in sickle cell disease. Pediatr Blood Cancer 2018;65:e26906.

21 Harris LM, Dreyer BP, Mendelsohn AL, et al. Liquid medication dosing errors by Hispanic parents: role of health literacy and English proficiency. Acad Pediatr 2017;17:403-10.

22 Wallace LS, Keenum AJ, DeVoe JE, et al. Women's understanding of different dosing Instructions for a liquid pediatric medication. J Pediatr Health Care 2012;26:443-50.

23 Yin HS, Parker RM, Sanders LM, et al. Pictograms, units and dosing tools, and parent medication errors: a randomized study. Pediatrics 2017;140:e20163237.
24 Yin HS, Parker RM, Sanders LM, et al. Liquid medication errors and dosing tools: a randomized controlled experiment. Pediatrics 2016;138. doi:10.1542/peds.2016-0357. [Epub ahead of print: 12 Sep 2016].

25 Yin HS, Dreyer BP, van Schaick L, et al. Randomized controlled trial of a pictogram-based intervention to reduce liquid medication dosing errors and improve adherence among caregivers of young children. Arch Pediatr Adolesc Med 2008;162:814-22. -

26 Yin HS, Mendelsohn AL, Fierman A, et al. Use of a pictographic diagram to decrease parent dosing errors with infant acetaminophen: a health literacy perspective. Acad Pediatr 2011;11:50-7. -

27 Williams TA, Wolf MS, Parker RM, et al. Parent dosing tool use, beliefs, and access: a health literacy perspective. $J$ Pediatr 2019;215:244-51.

28 Torres A, Parker RM, Sanders LM, et al. Parent preferences and perceptions of milliliters and Teaspoons: role of health literacy and experience. Acad Pediatr 2018;18:26-34.

29 Leyva M, Sharif I, Ozuah PO. Health literacy among Spanishspeaking Latino parents with limited English proficiency. Ambul Pediatr 2005;5:56-9.

30 McMahon SR, Rimsza ME, Bay RC. Parents can dose liquid medication accurately. Pediatrics 1997;100:330-3.

31 Yaffe SJ, Bierman CW, Cann HM, et al. Inaccuracies in administering liquid medication. Pediatrics 1975;56:327-8.

32 Yin HS, Parker RM, Sanders LM, et al. Liquid medication errors and dosing tools: a randomized controlled experiment. Pediatrics 2016;138:11.

33 Dowse R, Ehlers MS. Pictograms in pharmacy. Int $J$ Pharm Pract 1998;6:109-18.

34 Dowse R, Ehlers M. Medicine labels incorporating pictograms: do they influence understanding and adherence? Patient Educ Couns 2005;58:63-70.

35 Dowse R, Ehlers MS. The evaluation of pharmaceutical pictograms in a low-literate South African population. Patient Educ Couns 2001;45:87-99.

36 Mansoor LE, Dowse R. Effect of pictograms on readability of patient information materials. Ann Pharmacother 2003;37:1003-9.

37 Houts PS, Doak CC, Doak LG, et al. The role of pictures in improving health communication: a review of research on attention, comprehension, recall, and adherence. Patient Educ Couns 2006;61:173-90.

38 Houts PS, Bachrach R, Witmer JT, et al. Using pictographs to enhance recall of spoken medical instructions. Patient Educ Couns 1998;35:83-8.

39 Katz MG, Kripalani S, Weiss BD. Use of pictorial AIDS in medication instructions: a review of the literature. Am J Health Syst Pharm 2006;63:2391-7.

40 Morrow DG, Hier CM, Menard WE, et al. Icons improve older and younger adults' comprehension of medication information. J Gerontol B Psychol Sci Soc Sci 1998;53:P240-54.

41 Ngoh LN, Shepherd MD. Design, development, and evaluation of visual AIDS for communicating prescription drug Instructions to nonliterate patients in rural Cameroon. Patient Educ Couns 1997;31:245-61.

42 Davis TC, Wolf MS, Bass PF, et al. Low literacy impairs comprehension of prescription drug warning labels. J Gen Intern Med 2006;21:847-51.

43 Kripalani S, Henderson LE, Chiu EY, et al. Predictors of medication self-management skill in a low-literacy population. J Gen Intern Med 2006;21:852-6.

44 Kalichman SC, Ramachandran B, Catz S. Adherence to combination antiretroviral therapies in HIV patients of low health literacy. J Gen Intern Med 1999;14:267-73.

45 Graham J, Bennett IM, Holmes WC, et al. Medication beliefs as mediators of the health literacy-antiretroviral adherence relationship in HIV-infected individuals. AIDS Behav 2007;11:385-92. 